\title{
Effects of High Frequency Modeling \& Grounding System Parameters on Transient Recovery Voltage across Vacuum Circuit Breakers for Capacitor Switching in Wind Power Plants
}

\author{
Nasim Akbari Kafshgari \\ University of Science and Technology \\ of Mazandaran \\ Behshahr, Iran \\ nasim.akbari90@gmail.com
}

\author{
Nabiollah Ramezani \\ University of Science and Technology \\ of Mazandaran \\ Behshahr, Iran \\ ramezani@mazust.ac.ir
}

\author{
Hassan Nouri \\ University of the West of England \\ Power Systems Research Laboratory \\ UWE Bristol, UK \\ hassan.nouri@uwe.ac.uk
}

\begin{abstract}
This paper investigates the transient recovery voltages across vacuum circuit breakers used for the switching shunt capacitor bank in wind power plants, which are connected to the power system. Consideration has been given to high frequency models of all power system components, such as, the transformer, wind power plant generator, cable, surge arrester, vacuum circuit breaker and grounding system. The initial phase of study reproduced the results of previous work. In the second phase, the influence of different parameters, such as, the grounding system network, current injection point location to the grounding system, soil resistivity, grounding system length segment and soil ionization phenomena in the grounding system on transient recovery voltage, have been investigated via EMTP$R V$. The results show that consideration of the high frequency behavior of the grounding system in wind power plants for prediction of transient recovery voltages is very important.

Index Terms-- Transient recovery voltage $(T R V)$; Capacitor bank; Vacuum circuit breaker(VCB); Back to back switching;
\end{abstract}

\section{INTRODUCTION}

The use of wind power plants for energy production is growing and many attempts have been made to improve the reliability of this type of energy production plant through effective grounding systems. Normally the system of grounding is through generators and transformers neutral points. Proper grounding systems will reduce excess transient over-voltages and hence increase the reliability and safety as well as reducing damage to the interfaced electrical equipment to the plant [1-2].

The switching overvoltage is considered to be an important cause of insulation breakdown in the windfarm. Zhang et al [3] report that there is a relationship between the switching overvoltage and the length of the feeder cable and the number of feeders that have been energized. Wu et al [4] discuss simulation results obtained from a number of switching scenarios in one of the Fuhai offshore wind farms in Taiwan. These switching scenarios include breaker closing or opening with wind-farm cable and substation transformer at no-load conditions, breaker opening when single-phase or three-phase faults appears in the cable of the offshore wind farm. In general one cause of over-voltages in power plants is capacitor switching [5]. Shunt capacitor bank switching is used for reactive power compensation, voltage regulation and power factor adjustment. Typically shunt capacitor bank switches are equipped with a series-connected inductor, which limits the inrush current during capacitor energization and the outrush current during capacitor bus faults [5]. A common application of this configuration is when two capacitor banks are connected to the same bus bar or located within the same vicinity. This is generally called back to back switching [6]. Switching is performed via circuit breakers, and hence, to achieve reliability, knowledge of the transient recovery voltage across the vacuum circuit breaker is necessary for determination of the breaker's dielectric withstand capability. A number of researchers have investigated issues related to the connection and disconnection of VCBs comprehensively in both time and frequency domains [7], [8] and [9]. The effects of different capacitor bank structures on transient recovery voltage across power systems' vacuum circuit breakers has been investigated by Badrzadeh [10] using PSCAD software. In a further investigation Badrzadeh et al [11] report that the stray capacitor of elements plays an important role on the Transient Recovery Voltages (TRV) at high frequencies. More recently Ghafourian et al [12] investigated the vacuum circuit breaker switching over voltages in an offshore wind farm. This work deals with the impact of VCB parameters (e.g. stray capacitance and withstand voltage ability) and cable length on the transformer terminal voltage during closing operation.

In this paper the reduction of Transient Recovery Voltage (TRV) across a Vacuum Circuit Breaker (VCB) will be studied. In section II, high frequency models of all elements of power systems are considered for this investigation within an EMTP-RV environment. Simulation results are composed of two parts. Part A-III shows a reproduction of the results of a previous work [10], which are used here as a bench mark. The bench mark paper investigates TRV across VCB which is the result of disconnection of capacitor banks to the plant. Part B-III reports the contribution of this paper where the results demonstrate that consideration of the high frequency model of the grounding system will lead to a more accurate prediction of TRV across VCBs for protection of plant equipment. Then in conjunction with the developed high 
frequency grounding system model investigated the impact of soil ionization phenomena on TRV magnitude which has previously not been considered.

\section{SYSTEM UNDER CONSIDERATION}

The simulation is carried out on a wind farm which is composed of six identical wind power generators. Each generator has a rating of $2 \mathrm{MW}$. The layout of this model is shown in Fig. 1. Step-up transformers (2.2 MVA, 690 V/20 $\mathrm{kV}$ ) are installed in the vicinity of the wind turbine towers. All step-up transformers are connected to the grid $(20 \mathrm{kV})$ via a two $\mathrm{Km}$ three phase single core underground (details shown in Appendix A). The grid is simulated as a voltage source behind impedance. The surge arrester is placed with the two capacitor banks which are rated 1.67 and $3.34 \mathrm{MVAr}$ respectively. The function of the capacitor banks is to provide reactive power to the plant when needed and to be disconnected in the event of a fault. The fault is assumed to be a three phase to ground fault occurring at bus 3 (midpoint of grid and windfarm connection) at time zero and clearing at $60 \mathrm{~ms}$. Also, the first opening attempt by the vacuum circuit breaker is initiated at 80 ms.

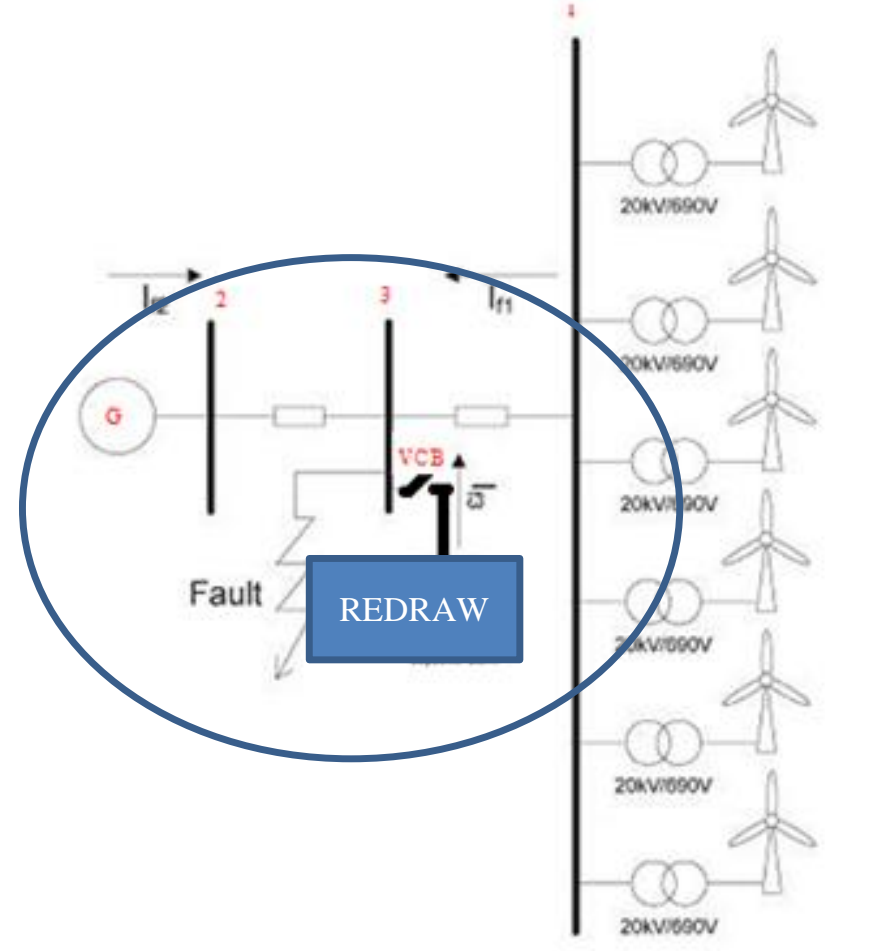

Figure 1

Fig. 1. System under consideration [10]

\section{A. Model of asynchronous generator}

It is well known that the influence of stray capacitance is more significant at high frequencies. In general the main stray capacitors of an induction machine include the following: $C_{s f}$ : Stator winding to frame capacitance $C_{s r}$ : Stator winding to rotor capacitance
$C_{r f}:$ Rotor to frame capacitance

The calculated capacitance between the windings and the stator frame $\mathrm{C}_{\mathrm{sf}}$ is typically in the order of 30-100 times higher than the capacitance between the winding and the rotor $\mathrm{C}_{\mathrm{sr}}$. Equation (1) is generally valid:

$$
C_{s f} \gg C_{r f} \gg C_{s r}
$$

It is therefore justifiable to neglect the stator winding to rotor and the rotor to frame capacitances which have a significantly smaller value compared to the capacitance between the winding and stator frame [11].

\section{B. Model of transformer}

In the transient study that involves frequencies up to a few $\mathrm{kHz}$, inclusion of the transformer stray capacitances in the transformer model is essential [13]. These parameters can often be determined by measurement from the actual transformers. Transformer capacitances have been represented by $\mathrm{C}_{\mathrm{H}}, \mathrm{C}_{\mathrm{L}}$, and $\mathrm{C}_{\mathrm{HL}}$ as shown in Fig. 2 where:

$C_{H}$ : Capacitance of $\mathrm{HV}$ winding to ground

$C_{L}$ : Capacitance of $\mathrm{LV}$ winding to ground

$C_{H L}$ : Capacitance between HV and LV windings

Wang et al [14] suggest that the values of $C_{L}$ and $C_{H L}$ are greater than those of $\mathrm{CH}_{\mathrm{H}}$, as shown by equation (2). This is due to the fact that the high voltage side requires more separation between windings and between windings and the core [15].

$$
C_{H L}>C_{L}>C_{H}
$$

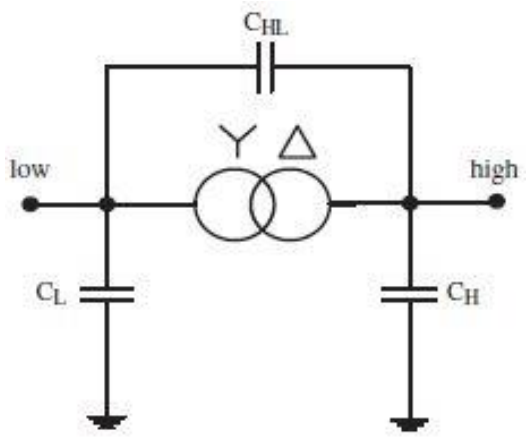

Fig. 2. Model of transformer [13]

\section{Model of cable}

In wind power plants, three phase, three core cables are commonly used for various connections to the grid. Here, two $\mathrm{Km}$ length, three single core cables of flat configuration with individual shielding are considered. The frequency dependent cable model within the EMTP-RV Software is used, which includes the traveling wave feature and a wide range of frequencies. Consideration of the geometry and material parameters, such as, relative permeability and earth resistance are essential for transient modeling and so is grounding of the cable sheath for the reduction of the transient waves [16]. Data of the cable model segment is described in Appendix A. 


\section{Model of surge arrester}

The IEEE Working Group 3.4.11 [17] proposed the frequency dependent model of Fig. 3, that includes the nonlinear resistance $A_{0}$ and $A_{1}$, separated by a R-L filter. For slow front surges the filter impedance is low and the nonlinear resistances are in parallel. For fast front surges filter impedance becomes high, and the current flows through the nonlinear resistance $A_{0}$. Since the characteristic $A_{0}$ has higher voltage for a given current, the result is the higher frequency, the higher residual voltage [18].The inductance $L_{1}$ and the resistance $R_{1}$ comprises the filter between the two varistors, since the inductance $L_{0}$ is associated with magnetic fields in the vicinity of the arrester. $R_{0}$ stabilizes the numerical integration and hence aids to avoid numerical oscillation and $\mathrm{C}$ represents the terminal-to-terminal capacitance, which is known as the external capacitance associated with the height of the arrester [17]. According to reference [19], the element's value of this model can be calculated using the arrester dimension.

For this study $A_{0}$ and $A_{1}$ are taken from the reference paper [10] and the computed values of other parameters are shown in Table I. Further details about arresters can be found in Appendix B.

Table I: The value of arrester parameters

\begin{tabular}{|c|c|c|c|c|c|}
\hline Parameters & $R_{0}-\Omega$ & $L_{0}-\mu \mathrm{H}$ & $R_{1}-\Omega$ & $L_{1}-\mu \mathrm{H}$ & $\mathrm{C}-\mathrm{nF}$ \\
\hline Values & 34.7 & 0.069 & 22.55 & 5.2 & 0.288 \\
\hline
\end{tabular}

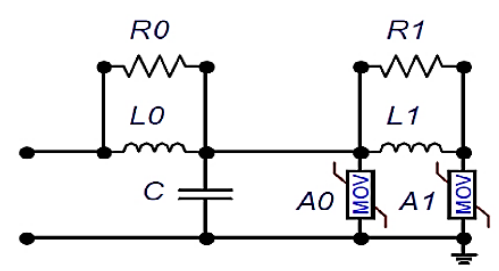

Fig. 3. Model of surge arrester [17]

\section{E. Model of vacuum circuit breaker}

As suggested by the international standard on the subject, the three main characteristics of vacuum circuit breakers, such as, chopping current value, the cold withstand voltage characteristic and the high frequency current quenching capability [20], have been considered in the implemented model.

Firstly, the value of the chopping current depends on different parameters, such as the contact material or the load surge impedance. The VCB model proposed by Borghetti et al [21] has been used in this study and the reference paper [10]. Here the selected chopping current of 5 A from [10] has been chosen in the modelling.

Secondly, representation of the dielectric strength associated with the open contacts in the vacuum is important in VCB modeling. The implemented linear expression for the $\mathrm{VCB}$ is as follows:

$$
u=A\left(t-t_{\text {open }}\right)+B
$$

Where $t_{\text {open }}$ is the contacts separation time, $A$ is the rate of dielectric strength rise and B is the TRV withstand voltage just before contact separation [21]. the selected chopping current of $5 \mathrm{~A}$ from [10] has been chosen in the modelling Finally, the VCB high frequency quenching capability is defined by (4).

$$
\frac{d i}{d t}=C\left(t-t_{\text {open }}\right)+D
$$

Where $\mathrm{C}$ is the rate of rise of the VCB high frequency quenching capability $D$ is the VCB quenching capability just before contact separation. The value of parameters $A, B, C$ and $\mathrm{D}$ is dependent on the specific VCB [21]. A high frequency capability VCB is assumed $350 \mathrm{~A} / \mu \mathrm{s}$.

The model also includes a RLC branch in parallel to the VCB in order to take into account the open contact gap stray capacitance, resistance and relevant inductance. The value of the RLC branch parameters, are typically [21]:

$$
L_{s}=50 \mathrm{nH} \quad, \quad C_{s}=100 \mathrm{PF} \quad, \quad R_{s}=100 \Omega
$$

Fig. 4 shows the implemented model of the vacuum circuit breaker in EMTP_RV.

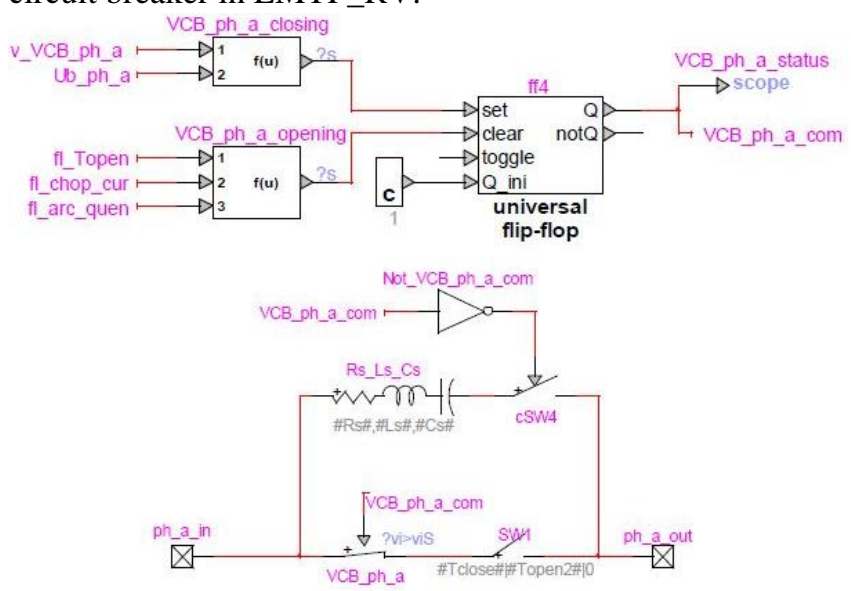

Fig. 4. Model of vacuum circuit breaker [21]

\section{F. Model of grounding system}

Transmission Line Modeling (TLM) methodology is a differential numerical technique having implementations in both time and frequency domains. As shown in Fig. 5 to model a grounding electrode, the equivalent circuit of the model is divided into several distributed segments and each segment is represented by a lumped circuit. Equations are provided to calculate the values of resistance, conductance, inductance and capacitance of horizontal and vertical electrodes. 


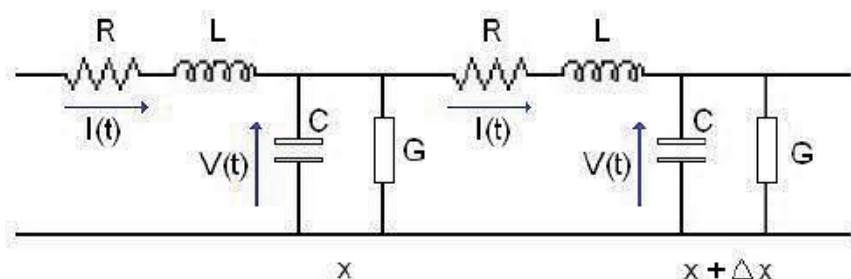

Fig. 5. TLM modeling of grounding system [22]

Equation (5) is used to calculate the resistance of both types of electrodes [22], as follows:

$$
R=\frac{\rho_{c} \cdot \Delta x}{\pi \cdot a^{2}}
$$

Where $\rho_{c}$ is the electric resistivity of the conductor.

From [23], G, L and C components for the vertical electrode can be calculated using (6), (7) and (8).

$$
\begin{aligned}
& G=\frac{2 \cdot \pi \cdot \Delta x}{\rho_{s} \cdot \ln \left(\frac{2 \cdot l}{a}\right)} \\
& L=\frac{\mu_{0} \cdot \Delta x}{2 \cdot \pi} \times \ln \left(\frac{2 \cdot l}{a}\right) \\
& C=\frac{2 \cdot \pi \cdot \varepsilon_{0} \cdot \varepsilon_{r} \cdot \Delta x}{\ln \left(\frac{2 \cdot l}{a}\right)}
\end{aligned}
$$

Equations (9), (10) and (11) can be used for the horizontal electrode [22].

$$
\begin{aligned}
& G=\frac{2 \cdot \pi \cdot \Delta x}{\rho_{s} \cdot\left[\ln \left(\frac{2 \cdot l}{\sqrt{2 \cdot a \cdot h}}\right)-1\right]} \\
& L=\frac{\mu_{0} \cdot \Delta x}{2 \cdot \pi} \times\left[\ln \left(\frac{2 \cdot l}{\sqrt{2 \cdot a \cdot h}}\right)-1\right] \\
& C=\frac{2 \cdot \pi \cdot \varepsilon_{0} \cdot \varepsilon_{r} \cdot \Delta x}{\left[\ln \left(\frac{2 \cdot l}{\sqrt{2 \cdot a \cdot h}}\right)-1\right]}
\end{aligned}
$$

Where $\varepsilon_{\mathrm{r}}$ is the relative permittivity, $\varepsilon_{0}$ is the vacuum permittivity, $\mu_{0}$ is the vacuum permeability, $h$ is the buried depth of the conductor, $l$ is the electrode length, a is the electrode radius, $\rho_{\mathrm{s}}$ is the electric resistivity of the soil and $\Delta \mathrm{x}$ is the segment length.

\section{G. Considering soil ionization phenomenon}

Another important parameter that needs to be considered in the high frequency modeling of the grounding system is the soil ionization phenomenon. In this phenomenon, the space around the conductor changes and conducts, increasingly so as it gets closer to the current injection point, as illustrated in Fig. 6. To consider this phenomenon in transient studies, the Transmission Line Model can be used, acceptably.

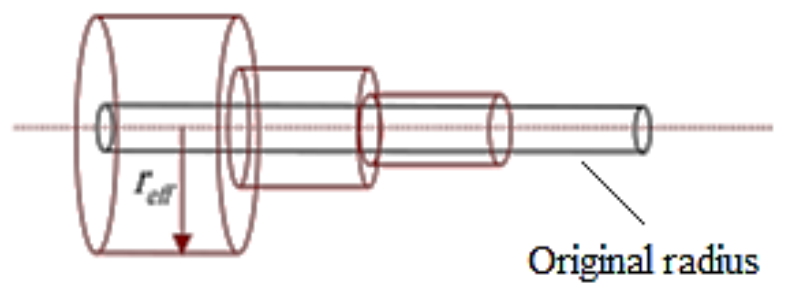

Fig. 6. Ground electrode and soil ionization phenomenon
According to [21], to consider the soil ionization it is necessary to calculate the time variable resistance and conductance values of the grounding system electrode. The following equations are used to calculate the resistance of both vertical and horizontal electrodes.

$$
\begin{aligned}
& R(t)=R \times \frac{1}{\sqrt{1+\frac{I(t)}{I_{g}}}} \\
& I_{g}=\frac{E_{c r} \cdot \rho_{s}}{2 \cdot \pi \cdot R^{2}} \\
& R=\frac{\rho_{c} \cdot \Delta x}{\pi \cdot a^{2}}
\end{aligned}
$$

Equations (15) and (16) calculate conductance values of vertical and horizontal electrode, respectively.

$$
\begin{aligned}
& G(t)=\frac{2 \cdot \pi \cdot \Delta x}{\rho_{s} \cdot \ln \left(\frac{2 \cdot l}{a}\right)} \times \frac{1}{\sqrt{1+\frac{I(t)}{I_{g}}}} \\
& G(t)=\frac{2 \cdot \pi \cdot \Delta x}{\rho_{s} \cdot\left[\ln \left(\frac{2 \cdot l}{\sqrt{2 \cdot a \cdot h}}\right)-1\right]} \times \frac{1}{\sqrt{1+\frac{I(t)}{I_{g}}}}
\end{aligned}
$$

$\mathrm{R}(\mathrm{t})$ and $\mathrm{G}(\mathrm{t})$ are the values of nonlinear resistance and conductance of the grounding system electrode. Where $I(t)$ is current passing through the electrode, $\mathrm{I}_{\mathrm{g}}$ is the initiation current of soil ionization and $\mathrm{E}_{\mathrm{cr}}$ is the electric field intensity that is often considered to be $300 \mathrm{kV} / \mathrm{cm} \mathrm{[23].}$

The flowchart proposed in this paper is shown in Fig. 7 for consideration of the soil ionization phenomenon in grounding systems.

In this flowchart, if the current I in the mth segment of the grounding electrode at the time step of $\mathrm{k}$ is greater than the critical current $\left(I_{g}\right)$, new values of $G(m, k)$ depending on the point $\mathrm{m}$ are calculated. If not all segments of an electrode in the step time of $\mathrm{k}$ are evaluated, the process will be continued for other segments of electrode, otherwise the next time step begins and previous stages are continued.

\section{SIMULATION OF CASE STUDY AND THE RESULTS}

In this section, the simulation results are compared and evaluated with results of previous work, considered here as reference work or benchmark results [10]. Then, new methods are provided for improved prediction of TRV in capacitor bank switching in wind power plants connected to power systems.

\section{A. Validation of simulation results with reference results}

In this study, Fig. 1 is implemented for different capacitor bank structures of Fig. 8 via EMTP_RV software. In Case 3 and Case 5 grading capacitors are used for increasing the dielectric strength of VCB. 


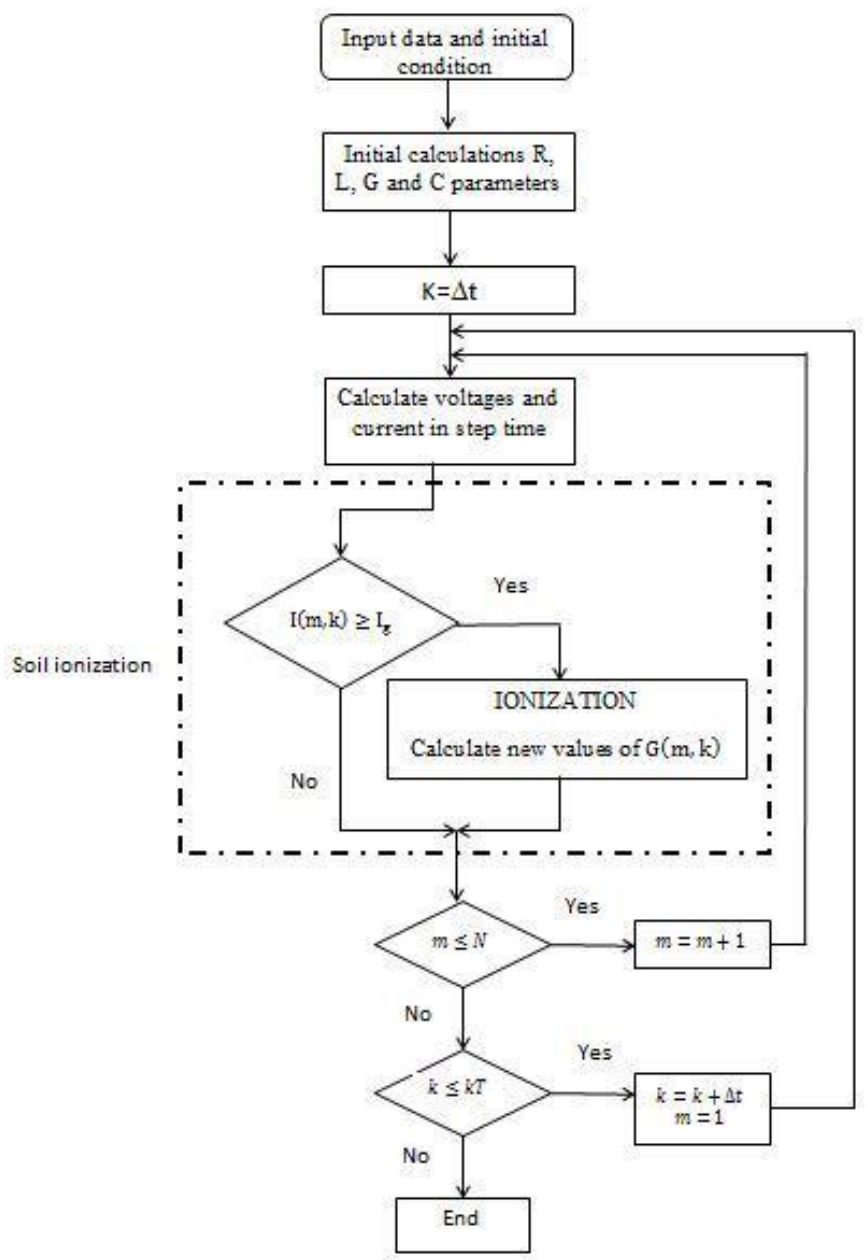

Fig. 7. Flowchart of considering soil ionization phenomenon in grounding system
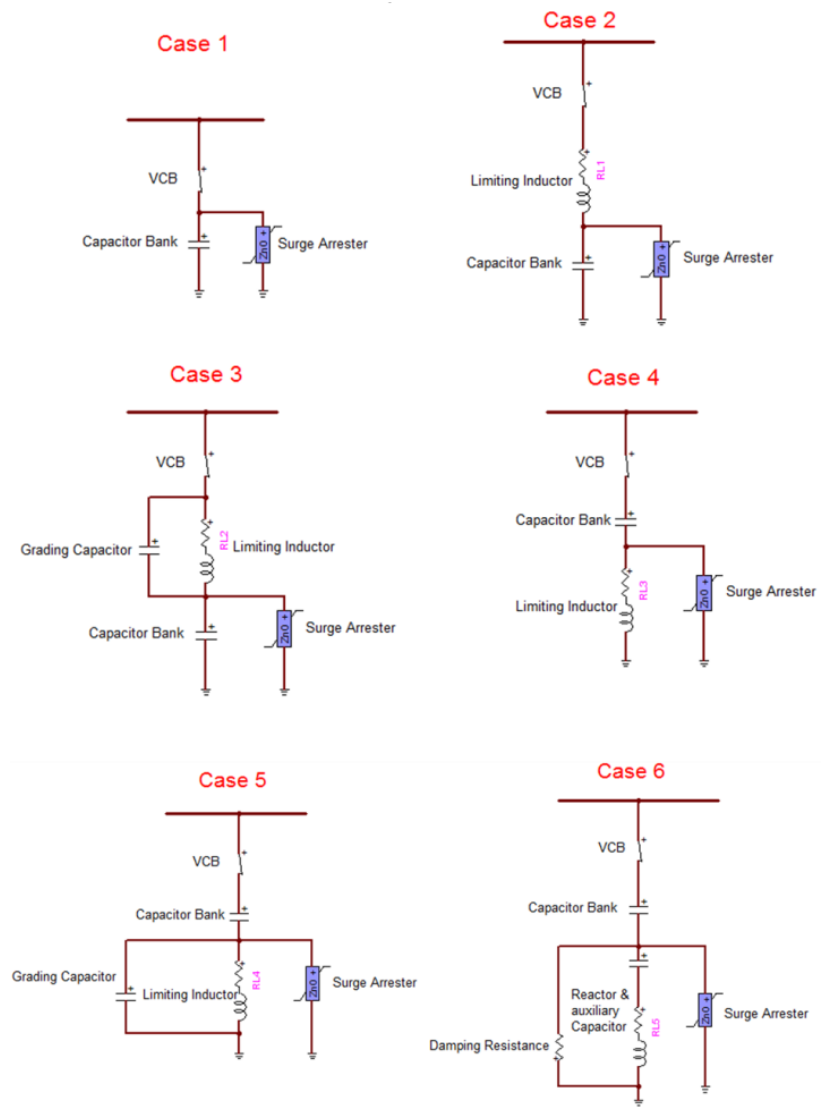

Fig. 8. Different structures of capacitor bank

Fig. 9 and Fig. 10 show comparisons of simulation results with results of [10] for two structures, Case 1 and Case 2. In addition, Table II summarizes the results of all cases.

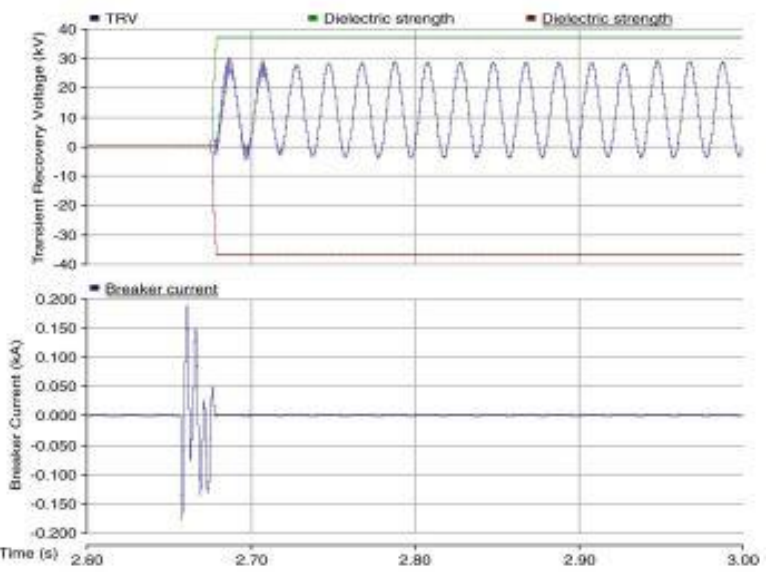

a. Reference [10] result 

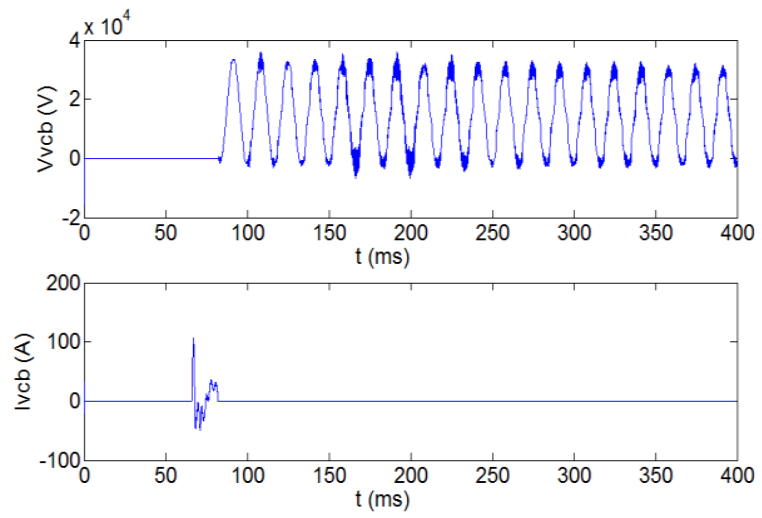

b. Simulation result

Fig. 9. Comparison voltage and current of the VCB for Case 1 structure with [10]

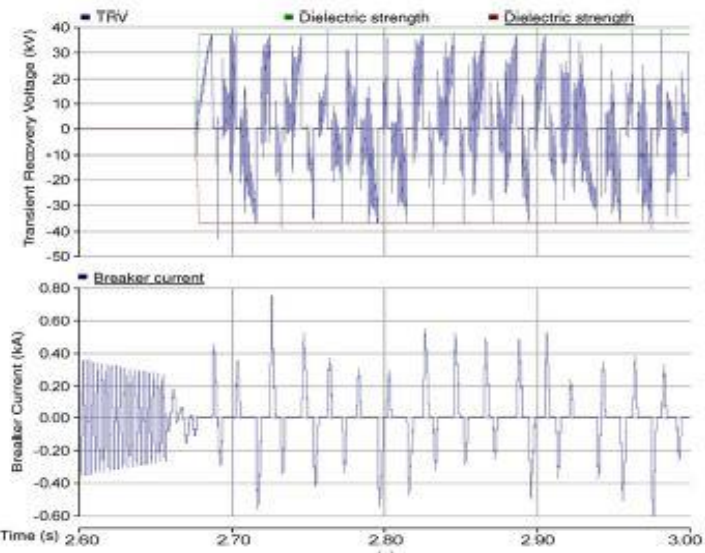

a. Reference $[10]$ results
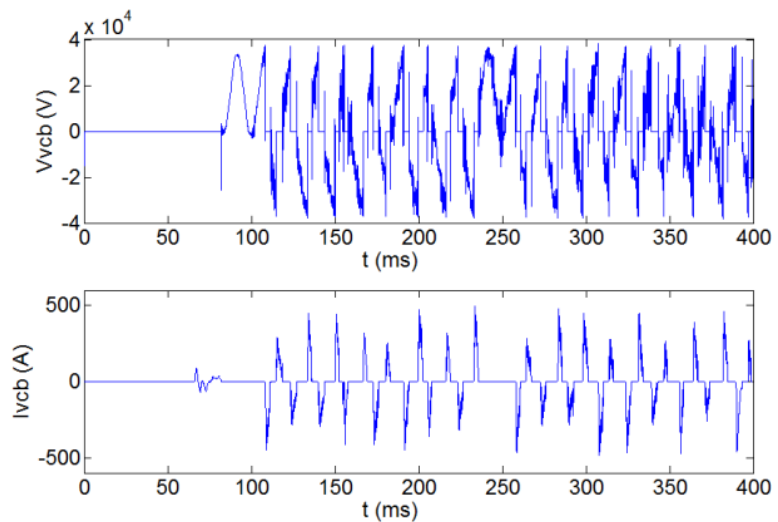

b. Simulation result

Fig. 10. Comparison voltage and current of the VCB for Case 2 structure with [10]
Table II: comparison of authors' results with reference results

\begin{tabular}{|c|c|c|c|c|}
\hline 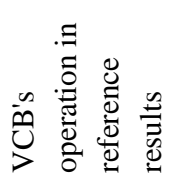 & 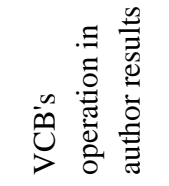 & 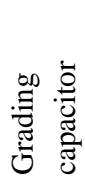 & 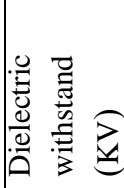 & 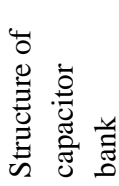 \\
\hline successful & successful & No & 37 & Case 1 \\
\hline unsuccessful & unsuccessful & No & 37 & Case 2 \\
\hline unsuccessful & unsuccessful & Yes & 37 & Case 3 \\
\hline unsuccessful & unsuccessful & No & 37 & Case 4 \\
\hline successful & successful & Yes & 37 & Case 5 \\
\hline successful & successful & No & 37 & Case 6 \\
\hline
\end{tabular}

As is clear from the results, operation of the capacitor bank VCB is the same in both cases obtained from the proposed procedure and [10]. The term "unsuccessful operation of VCB" corresponds to cases when TRV across the VCB is greater than its withstand voltage [24].

\section{B. Effect of Mesh grounding system on TRV across VCB in wind power plants}

Since the TRV across the VCB for Case 2 is unresolved through use of the grading capacitor, different grounding system configurations can lead to a reduction in TRV. Fig. 11 and Fig. 12 show the $2 \times 2 \mathrm{~m}^{2}$ mesh grounding system and the results obtained using the TLM method with various square shapes and a buried depth of $1 \mathrm{~m}$ respectively, for both the generator and transformer. The TRV across the VCB yields lower values than their respective dielectric strengths. In this case, the "a" phase current of the VCB is reduced compared to a case without modeling a grounding system.

In the proceeding sections, changing the current injection point to the grounding system, the impact of changing the segment length of the grounding system, the impact of different soil resistivity and soil ionization for the reduction of TRV are illustrated.
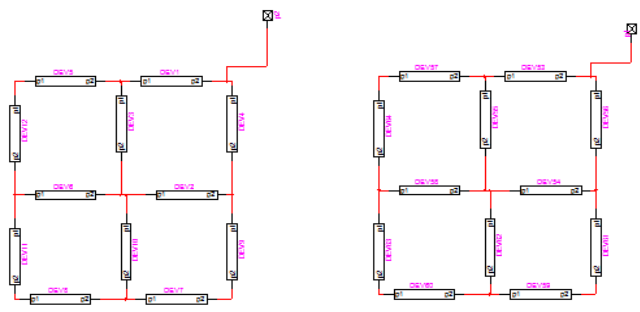

Fig. $11.2 \times 2 \mathrm{~m}^{2}$ mesh grounding system 

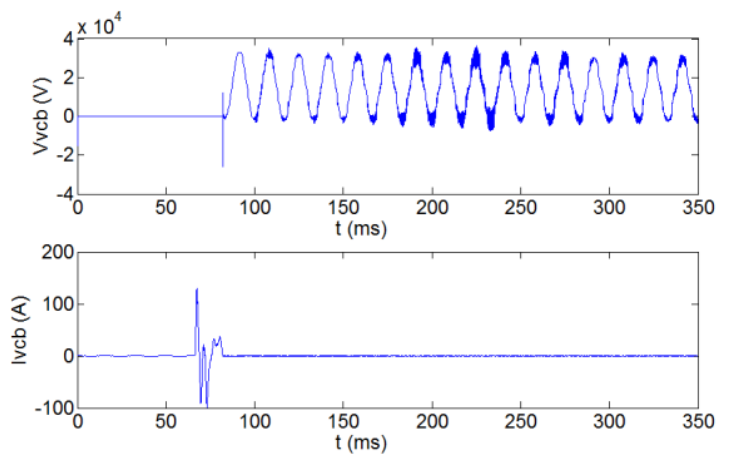

Fig. 12. voltage and current across VCB using $2 \times 2 \mathrm{~m}^{2}$ grounding system

1) Impact of changing the current injection point to the grounding system

Simulations are performed for both connections to the corner and connections to the center of the grounding system. Results are provided in Table III .

Table III: The effect of current injection point to grounding system

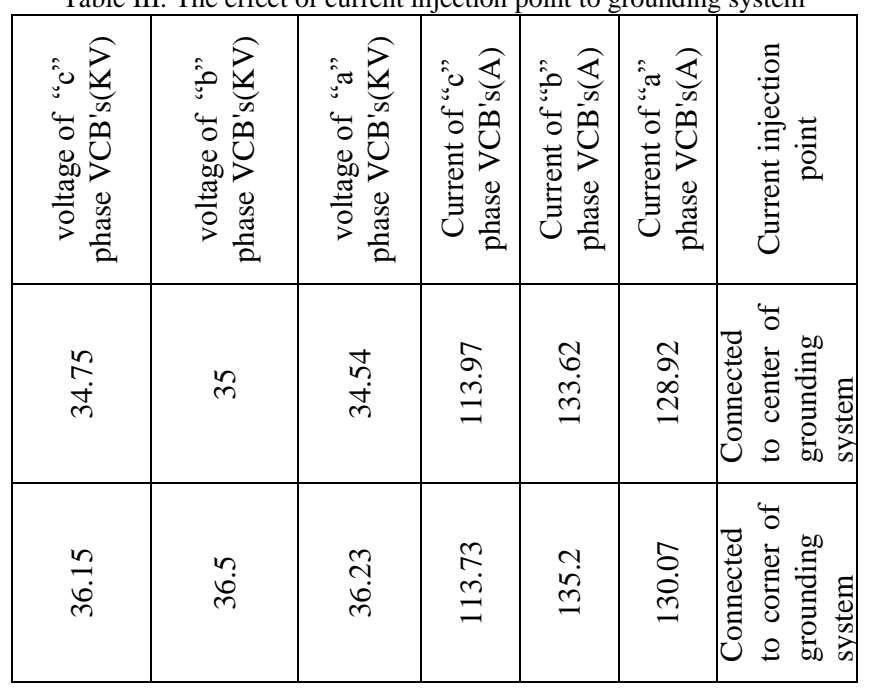

As is clear from the results, the location of the connection of the neutral point to the grounding system can be effective for decreasing the TRV across the VCB. For the same grounding system, the TRV and the current of the VCB for an injection point at the Centre is smaller with respect to the injection point at the corner. In the case of the injection point at the corner, the inductance of conductors will be considerable and will prevent the current from passing through the grounding system towards other directions. But for a case of injection point at the center, the grounding system shows small inductive effect.

2) Impact of changing the segment length of grounding system

To investigate the effect of changing the segment length $(\Delta \mathrm{x})$ on the voltage and current of the VCB, simulations are carried out for lengths of 2,1 and $0.5 \mathrm{~m}$ in $2 \times 2 \mathrm{~m}^{2}$ grounding systems. Table IV shows the different simulation results for one of the phases of the VCB.

Table IV: The effect of different length of $\Delta \mathrm{x}$ on VCB voltage and current

\begin{tabular}{|c|c|c|c|}
\hline $\begin{array}{c}\text { VCB } \\
\text { operation }\end{array}$ & $\begin{array}{c}\text { voltage of } \\
\text { "a" phase } \\
\text { VCB's(KV) }\end{array}$ & $\begin{array}{c}\text { Current of } \\
\text { "a" phase } \\
\text { VCB's(A) }\end{array}$ & $\begin{array}{c}\text { Length of } \\
\Delta x(\mathrm{~m})\end{array}$ \\
\hline unsuccessful & 38.1 & 479.7 & 2 \\
\hline successful & 36.23 & 130.07 & 1 \\
\hline successful & 34.65 & 128.8 & 0.5 \\
\hline
\end{tabular}

Since the injection current of grounding system electrodes to the soil is dependent on electrode material, its properties therefore have a nonlinear structure. Voltage and current reduction across the breaker can be achieved through a reduction in the segment length of the grounding system and by increasing the number of grounding system meshes.

\section{3) Impact of different soil resistivity}

To investigate the effects of different soil resistivity, simulations are performed for resistivity of 2000,1000, 700 and $300 \Omega$.m in a $2 \times 2 \mathrm{~m}^{2}$ grounding system. Table V shows the results of voltage and current for the "b" phase of the VCB.

It can be concluded that the amount of VCB current and voltage will be lower if the value of the $\rho_{s}$ decreases. Reduction of soil resistivity causes an increase in the conductance of grounding system electrodes. Therefore in rocky areas where $\rho_{\mathrm{s}}$ has a high value, to achieve successful operation of VCB a greater dimension of the grounding system is required.

Table V: The effect of changing soil resistivity on VCB voltage and current

\begin{tabular}{|c|c|c|c|}
\hline $\begin{array}{c}\text { VCB's } \\
\text { operation }\end{array}$ & $\begin{array}{c}\text { Voltage of } \\
\text { "b" phase } \\
\text { VCB's (KV) }\end{array}$ & $\begin{array}{c}\text { Current of } \\
\text { "b" phase } \\
\text { VCB's (A) }\end{array}$ & $\begin{array}{c}\text { Soil resistivity } \\
(\Omega . \mathrm{m})\end{array}$ \\
\hline Unsuccessful & 37.22 & 445.8 & 2000 \\
\hline Successful & 36.5 & 135.2 & 1000 \\
\hline Successful & 35.94 & 134.96 & 700 \\
\hline Successful & 34.95 & 134.15 & 300 \\
\hline
\end{tabular}

\section{4) The impact of soil ionization phenomenon}

To investigate soil ionization, simulations are performed for $2000,1000,700$ and $300 \Omega . m$ of soil resistivity in $2 \times 2 \mathrm{~m}^{2}$ grounding systems.

Table VI provides results of the voltage and current across "b" phase of the VCB, in cases with and without consideration of soil ionization.

Soil ionization phenomenon makes the soil around the grounding electrode conductive. This conductivity has the same effect as increasing the radius of the grounding electrode. Therefore, consideration of this phenomenon results in reduction of voltage and current magnitude across the VCB. Furthermore, according to equation (9), increasing 
the amount of $\rho_{s}$ decreases $G$, increases $R$ and reduces the magnitude of the ground current. Similarly, according to equation (13) any increase in soil resistivity $\left(\rho_{\mathrm{s}}\right)$ value causes reduction in the ground critical current $\left(I_{g}\right)$ and results in a reduction of voltage and current magnitude across the VCB.

Table VI: The effect of considering soil ionization on voltage and current of

\begin{tabular}{|c|c|c|c|c|}
\hline $\begin{array}{c}\text { Voltage of } \\
\text { "b" phase } \\
\text { VCB's } \\
\text { (KV) with } \\
\text { ionization }\end{array}$ & $\begin{array}{c}\text { Current of } \\
\text { "b" phase } \\
\text { VCB's (A) } \\
\text { with } \\
\text { ionization }\end{array}$ & $\begin{array}{c}\text { Voltage of } \\
\text { "b" phase } \\
\text { VCB's } \\
(\mathrm{KV}) \\
\text { without } \\
\text { ionization }\end{array}$ & $\begin{array}{c}\text { Current of } \\
\text { "b" phase } \\
\text { VCB's (A) } \\
\text { without } \\
\text { ionization }\end{array}$ & $\begin{array}{c}\text { Soil } \\
\text { resistivity } \\
(\Omega . m)\end{array}$ \\
\hline 36.1 & 134.45 & 37.22 & 445.8 & 2000 \\
\hline 34.78 & 133.93 & 36.5 & 135.2 & 1000 \\
\hline 36.5 & 135.128 & 35.94 & 134.96 & 700 \\
\hline 33.9 & 134.98 & 34.95 & 134.15 & 300 \\
\hline
\end{tabular}

\section{CONCLUSION}

This paper has investigated the TRV across VCBs used for capacitor bank switching via modeling of grounding systems in EMTP_RV software. From the simulation results, it can be concluded that implementation of a mesh grounding system within wind power plants reduces the TRV across VCBs in capacitor bank switching. A variation of parameters, such as, the location of the high frequency current injection point to the grounding system, the segment length, soil resistivity and soil ionization phenomenon, is also effective in forecasting TRV.

Also, different locations for the current injection point to the grounding system results in different amounts of current and voltage appearing across the breaker. For example, if the current injection point is connected to the center of the grounding system a greater decrease in TRV across the breaker can be observed due to equal impedance conditions. Furthermore, a reduction in the segment length of the grounding system via an increase in the number of grounding system meshes and hence more uniformity in the path of current to the earth causes a decrease in voltage and current across the breaker. The voltage and current across breakers increases in rocky ground where the soil resistivity is high.

Finally, the soil ionization phenomenon causes a reduction in the breaker current and voltage due to the conductivity of soil around the electrode.

\section{REFERENCES}

[1] D. Cavka, D. Poljak, V. Doric, R. Goic, "Transient analysis of grounding systems for wind turbines," Renewable Energy, Vol. 43, 2012, pp. 284-291.

[2] M. Popov, L. Grcev, H. Høidalen, B. Gustavsen and V. Terzija, "Investigation of the Overvoltage and Fast Transient Phenomena on Transformer Terminals by Taking into Account the Grounding Effects," IEEE Transaction on Industry Applications, Vol. 51, No 6, 2015, pp 5218-5227.
[3] T. Zhang, L. Sun, and Y. Zhang, "Study on Switching Overvoltage in Off-Shore Wind Farms," IEEE Transactions on Applied Superconductivity, Vol. 24, No. 5, 2014, pp 1-5.

[4] Y.K. Wu, W. Hs. Tsai and C.J. Chou, "Study on Switching Overvoltage in Fuhai Offshore Wind Farm in Taiwan," 10th International Conference on Advanced in Power System Control, operation and Management, APSCOM 2015, pp 1-6.

[5] R. Natarajan, Power System Capacitors. London, U.K. CRC Press, 2005.

[6] T. A. Bellei, E. Camm, and G. Ransom, "Current-limiting inductors used in capacitor bank applications and their impact on fault current interruption," IEEE Pest \& D Conf. Atlanta, USA, 2001, pp. 603-607.

[7] M. Popov. M, R.P.P. Smeets, van der, L Sluis, de, H Herdt nand J. Declercq, "Experimental and theoretical analysis of vacuum circuit breaker prestrike effect on a transformer," IEEE Transactions on Power Delivery, Vol. 24, No. 3, 2009, pp 1266-1275.

[8] L. Liljestrand et al, "Vaccum Circuit Breaker and Transformer Interaction in a cable System," CIRED 22nd International Conference on Electricity Distribution, Stockholm, Paper 0412, June 2013, pp 1-5.

[9] M. Popov, L. van der Sluis, GC. Paap, "Investigation of the circuit breaker reignition overvoltages caused by no-load transformer switching surges," European Transactions on Electrical Power, 11(6), 200, pp 413-422.

[10] B. Badrzadeh, "Transient Recovery Voltages Caused by Capacitor Switching in Wind Power Plants," IEEE Trans. Ind. Appl, Vol. 49, No. 6, may. 2013.

[11] B. Badrzadeh, M. Hgdahl, and E. Isabegovic, "Transients in wind power plants-Part I : Modeling methodology and validation," IEEE Trans. Ind. Appl., Vol. 48, No. 2, 2012, pp. 794-807.

[12] S. M. Ghafourian, I. Arana, J. Holbøll, T. Sørensen, M. Popov, and V. Terzija, "General Analysis of Vacuum Circuit Breaker Switching Overvoltages in Offshore Wind Farms," IEEE Transactions on Power Delivery, Vol.. 31, No. 5, 2016, pp 2351-2359.

[13] Amr M. Abd-Elhady, Nehmdoh A. Sabiha, and Mohamed A. Izzularab , "High-frequency modeling of Zafarana wind farm and reduction of backflow current-over voltages," Int. Trans. Electri. Energ. Syst, vol. 24, no. 4, 2014, pp. 457-476.

[14] X. Wang, P. Wilson, J. Zhou, D. Muthumuni, D. Kell, and K. Louie, "Transient Recovery Voltage Investigation in the Application of $15 \mathrm{KV}$ Circuit Breaker Failure," Proc. Int. Conf. on Power Systems Transients. Canada, pp. 224, 2005.

[15] A. Greenwood, " Electrical Transients in Power Systems," 2nd edn, John Wiley \& Sons, 2nd edn, 1991.

[16] B. Gustavsen, J. A. Martinez, and D. Durbak, "Parameter Determination for Modeling System Transients-Part II: Insulated cables,"IEEE Trans. Power Del, vol. 20, no. 3, July. 2005.

[17] P. Unahalekaka, "Simplified Modeling of Metal Oxide Surge Arresters," in Proc 11 ${ }^{\text {th }}$ EMSES, vol. 56, 2014, pp. 92-101.[online]. Available: www.sciencedirect.com.

[18] Christos A. Christodoulou et al, "Simulation of Metal Oxide Surge Arresters Behavior," IEEE Power Electronics Specialists Conference, 2008, pp 1-5.

[19] J. Furgal, and S. K. Omar Dau, "Modeling of Metal Oxide Surge Arresters as Elements of Overvoltage Protection systems," Electrotechnika I Elektronika Tom27. Zeszyt1, 2008.

[20] B. Kondala Rao And G. Gajjar, "Development And Application Of Vacuum Circuit Breaker Model in Electromagnetic Transient Simulation,'IEEE Conf. Power India, 2006.

[21] A. Borghetti, F. Napolitano, C. A. Nucci, M. Paolone, M. Sultan, and N. Tripaldi, "Transient Recovery Voltages in Vacuum Circuit Breakers Generated by the Interruption of Inrush Currents of Large Motors," Proc. Int. Conf. On Power Systems Transients. Netherlands, Jun. 2011.

[22] Gazzana, S. Bretas, D. Dias, M. Telló, P. Thomas and C. Christopoulos, "Effective Length Study of Grounding Electrodes Reached by Lightning Based on Transmission Line Modeling Method," IEEE conf. EMC, 2012. 
[23] Gazzana, S. Bretas, D. Dias, M. Telló, P. Thomas and C. Christopoulos, "The transmission line modeling method to represent the soil ionization phenomenon in grounding systems, " IEEE Trans. Magnetics, vol. 50, no. 2, February 2014.

[24] S. M. Wong , L. A. Snider, and E. W. C. Lo, "Overvoltages and reignition behavior of vacuum circuit breaker," International Conference on Power Systems Transients - IPST 2003, New Orleans, USA, pp 1-6.

[25] J. A. Martinez and D. W. Durbak , "Parameter determination for modeling systems transients-Part V: Surge arresters," IEEE Transactions on Power Delivery, Vol. 20, No. 3, 2005, pp 2073-2078.

[26] M. Nafar, G. Gharehppetian and T. Niknam, "A novel parameter Estimation Method for metal oxide surge arrester model," Sadhana, vol. 36, Part. 6, 2011, pp. 941-961.

[27] M. Nafar, GH. Solookinegad and M. Jabbari, "Comparison of IEEE and Pinceti Models of Surge Arresters, " Research Journal of Engineering Sciences, vol. 3, No. 5, 2014, pp. 32-34.

[28] Daniel W. Durbak, "Surge Arrester Modeling," IEEE Power Engineering Society Winter Meeting, 2001, pp 1-3.

\section{APPENDIX A: CABLE PARAMETERS}

The construction of a two Km, three phase, and single core underground cable in flat formation is shown in Fig. A1. Its corresponding EMTP-RV data is displayed in Table A1.

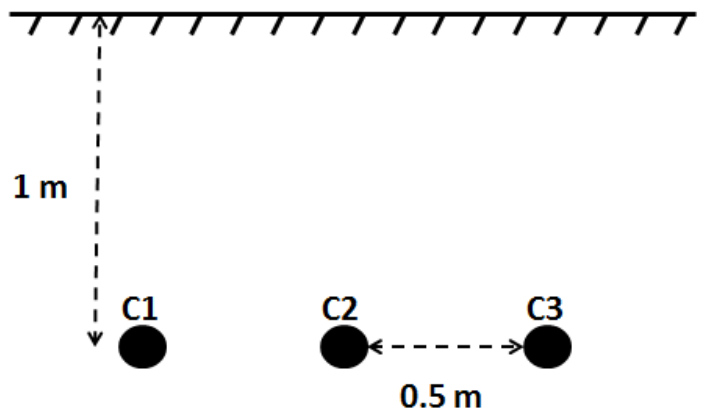

Fig. 13 Three single core cables of flat configuration

Table A1: EMTP_RV cable data

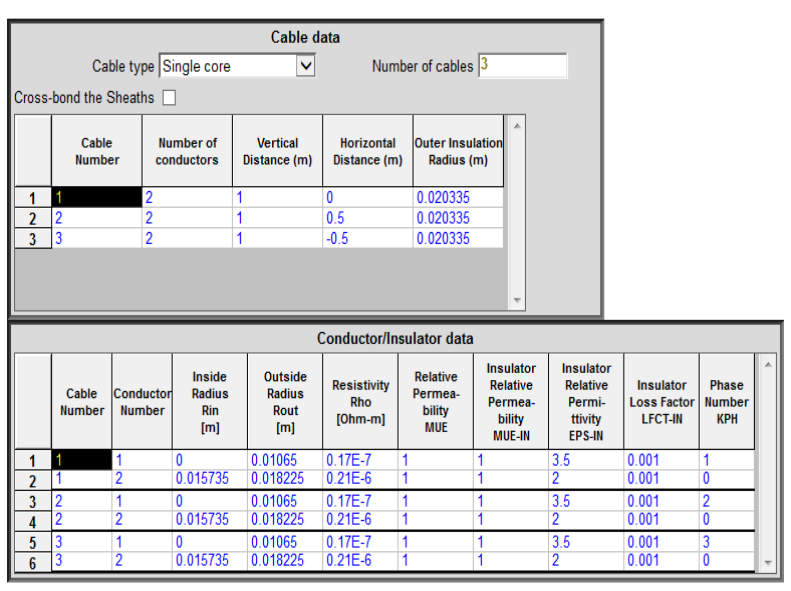

\section{APPENDIX B: SURGE ARRESTER PARAMETERS}

The IEEE Working Group 3.4.11 [17] proposed the model of Fig. 3, including the non-linear resistance $A_{0}$ and $A_{1}$, separated by a R-L filter. For slow front surges the filter impedance is low and the non-linear resistances are in parallel. For fast front surges filter impedance becomes high, and the current flows through the nonlinear resistance $A_{0}$. Since the characteristic $A_{0}$ has higher voltage for a given current, the result is the higher frequency, the higher residual voltage[18].The inductance $L_{1}$ and the resistance $R_{1}$ comprise the filter between the two varistors, since the inductance $L_{0}$ is associated with magnetic fields in the vicinity of the arrester. $R_{0}$ stabilizes the numerical integration and $\mathrm{C}$ represents the terminal-to-terminal capacitance. The equations for the above parameters [17] are given as:

$$
\begin{aligned}
& L=\frac{15 d}{n} \mu H \\
& R 1=\frac{65 d}{n} \Omega \\
& L o=\frac{0.2 d}{n} \mu H \\
& R o=\frac{100 d}{n} \Omega \\
& C=\frac{100 n}{d} p F
\end{aligned}
$$

where $d$ is the length of arrester column in meters and $n$ is the number of parallel columns of meta-oxide disks. The surge arresters have an extremely high resistance during normal operating voltages because conduct little or no current and have a relatively low resistance during transient overvoltages without causing a fault. It is known that they have a highly non-linear voltage versus current characteristic [25]. The per unit V-I characteristic of the varistors (A0 and A1) is shown in Fig. B1 and presented numerically in Table $\mathrm{B} 1$ respectively.

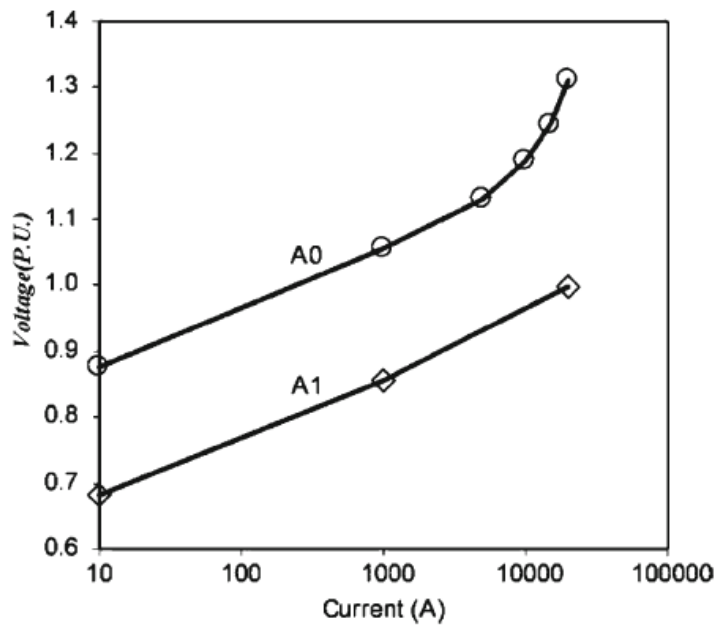

Fig. B1 non-linear V-I characteristic $A_{0}$ and $A_{1}$ [26] 
Table B1: Data for estimated $A_{0}$ and $A_{1}$ [27]

\begin{tabular}{|c|c|c|}
\hline \multirow{2}{*}{ Current (kA) } & \multicolumn{2}{|c|}{ Voltage (per unit of $\mathbf{V}_{\mathbf{1 0}}$ ) } \\
\cline { 2 - 3 } & $\mathbf{A}_{\mathbf{0}}$ & $\mathbf{A}_{\mathbf{1}}$ \\
\hline 0.01 & 0.875 & --- \\
\hline 0.1 & 0.963 & 0.769 \\
\hline 1 & 1.050 & 0.850 \\
\hline 2 & 1.088 & 0.894 \\
\hline 4 & 1.125 & 0.925 \\
\hline 6 & 1.138 & 0.938 \\
\hline 8 & 1.169 & 0.956 \\
\hline 10 & 1.188 & 0.969 \\
\hline 12 & 1.206 & 0.975 \\
\hline 14 & 1.231 & 0.988 \\
\hline 16 & 1.250 & 0.994 \\
\hline 18 & 1.281 & 1 \\
\hline 20 & 1.313 & 1.006 \\
\hline
\end{tabular}

The V-I characteristic is dependent upon waveshape of the arrester current. Currents with a faster rise time will result in higher peak voltages. Manufacturers test their surge arresters with a typical current pulse $10 \mathrm{kA}$ peak with an $8 \times 20$ microsecond waveshape and record a peak voltage known as the reference voltage V10. The V-I curves often use the V10 value as the $1.00 \mathrm{pu}$ value. The V-I curve can be determined by multiplying the per unit arrester voltages by the V10 for that rating. The choice of arrester V-I characteristic depends upon the type of transient being simulated. The V-I characteristic depends upon waveshape of the arrester current. Currents with a faster rise time will result in higher peak voltages. Manufacturers often publish several curves. The 8 × 20 microsecond wave applies for typical lightning surge simulations. The 36 x 90 microsecond wave applies to switching surge simulations. The $1 \mathrm{~ms}$ characteristic wave applies to low frequency phenomena. Manufacturers may supply min and max curves for each test waveshape. The max curve is generally used since it results in the highest overvoltages and conservative equipment insulation requirements. The min curves are used to determine the highest energy levels absorbed by the arrester [28]. 